\title{
Emotions and Self-efficacy as Mediators of Pre-Service Teachers' Adoption of Digital Tools
}

\author{
Wajeeh Daher ${ }^{1 *}$, Nimer Baya'a ${ }^{1}$, Ahlam Anabousy ${ }^{1,2}$ \\ ${ }^{I}$ Al-Qasemi Academic College of Education, Baqa El-Garbiah, Israel \\ ${ }^{2}$ Kibbutzim College of Education, Technology and the Arts, Tel-Aviv, Israel
}

\begin{abstract}
The present research examines whether the pre-service teachers' preparation in using digital tools in their teaching develops their acceptance of these tools for teachings. The research also examines the mediation of self-efficacy, anxiety of using digital tools for teaching mathematics and science and enjoyment of this use between the constructs of acceptance of digital tools for teaching. We used the TAM questionnaire in addition to scales that measure enjoyment, self-efficacy and anxiety. Forty-eight mathematics and science pre-service teachers participated in the study. We analyzed the collected data using SPSS 21 . The research results indicate that the pre-service teachers' preparation resulted in significant differences in their scores of affective and usage constructs associated with their acceptance of digital tools for mathematics and science teaching, except in the scores of anxiety. Self-efficacy proved to be a partial mediator between attitude and intention-to-use. Enjoyment proved to be a partial mediator between ease-of-use and attitude, but not between usefulness and attitude. Moreover, enjoyment proved to be a partial mediator between attitude and intention-to-use. These findings contribute to the understanding of mediators that affect the acceptance of digital tools for teaching.
\end{abstract}

\section{Keywords:}

Pre-Service Teachers;

Preparation Model;

Digital Tools;

Mathematics;

Technology Acceptance Model (TAM).

\section{Article History:}

Received: $\quad 30 \quad$ June 2021

Revised: 25 August 2021

Accepted: $\quad 04 \quad$ September 2021

Published: $01 \quad$ October 2021

\section{1- Introduction}

In the present paper, we describe a model for preparing pre-service teachers in the use of digital tools in teaching and the effect of this preparation on some affective and behavioral aspects of the usage of these tools in the classroom. Two of the factors that affect teachers' use of technological tools in their teaching are their orientations towards this use and the value of this use [1]. In the present research, we are interested in the previous two constructs, among other constructs, as constructs that could affect teachers' use of digital tools in the classroom. We utilize the Technology Acceptance Model (TAM) of Davis [2] as a framework for such analysis. We are aware that other frameworks could be used to analyze the studied issue [3], but we chose the TAM framework as it suits the analysis of the acceptance of digital tools for teaching the subject matter, which is one aspect of pedagogical technological content knowledge (PTCK) [4].

Following, we present first the literature review that addresses the different topics of the present research. Second, we elaborate on the research rationale, goals and questions, and third we address the methodology that we followed in the present research. Fourth, we present the findings of the research, then the discussion and finally the conclusions.

\footnotetext{
* CONTACT: daherwajeeh@gmail.com
}

DOI: http://dx.doi.org/10.28991/esj-2021-01301

(C) 2021 by the authors. Licensee ESJ, Italy. This is an open access article under the terms and conditions of the Creative Commons Attribution (CC-BY) license (https://creativecommons.org/licenses/by/4.0/). 


\section{2- Literature Review}

\section{2-1- Technology in the Mathematics Classroom}

Technology is suggested as an effective tool for the facilitation of students' learning in the mathematics classroom. This efficacy is due to the advantages of the integration of technology to support the different aspects of students' learning of mathematics. Researchers were interested, at the beginning, mainly with the potentialities of the technology for students' investigation of mathematical ideas. Geiger et al. [5] say that technology was used by teachers mainly to develop students' competencies in learning mathematics. These are the cases in Daher [6], as well as in Anabousy and Tabach [7], who investigated how applets helped students investigate and solve mathematical problems. Researchers became interested in the contribution of technology to other aspects of students' learning to show the contribution of technology to these aspects. Examples on these aspects are: students' emotions [8], students' positioning [9], the relationship between positioning and emotions in the presence of technology [10], students' metacognition [11], students' distance learning [12] and the relationship between metacognition and other aspects in the presence of technology [13]. Researchers also studied the community aspect [14], and the identity aspect [15] as influenced by technology presence. Despite these advantages, researchers pointed out that the potential of digital technologies in the mathematics classroom is poorly exploited because technology integration is quite limited [16].

\section{2-2- Pre-service and In-Service Teachers' Preparation for Using Technology in the Classroom}

Researchers pointed at the complexity of technology integration in the classroom, suggesting "teacher barrier" as the most important factor that hinders technology integration [16]. This necessitates preparing pre-service and in-service teachers for this integration. This preparatopm could affect pre-service teachers' readiness to integrate technology in their teaching. Jacobsen, Clifford and Friesen [17] studied preservice teachers' reluctance to infuse technology in their learning and student teaching, where this reluctance would not bring the skills and experiences needed to transform the educational practices in the classrooms. The authors argue that the reasons that lie behind this reluctance could be the over-emphasize on software applications rather than technology-infused curriculum design. A related reason is that the education of preservice teachers does not demonstrate effective infusion of technology in all subject areas. The authors suggest that one way to overcome this situation is to place preservice teachers in technology-enhanced classrooms in which experienced teachers demonstrate new ways of teaching and learning with technology. The previous argument of Jacobsen et al. [17] is still valid nowadays as more research implies the importance of teaching-in-context as encouraging pre-service teachers' adoption of technology as basis for their teaching [18]. Hedberg [19] also addressed the effectiveness of professional development (PD) programs for technology integration in the classroom. To be effective, PD needs to focus on instruction and how the use of technology will make learning more efficient. In the last decade, researchers shed light on the potential of collaboration between teachers in the context of their preparation to integrate technology. So, they suggested PD program designs such as the community-of-inquiry based PD programs, arguing that this design facilitates teachers' integration of technology in the mathematics classroom [1, 20]. In detail, Jaworski [20] suggested the inquiry cycle as a design for developing teaching practices. This cycle includes planning, acting and observing, reflection and analysis, and feedback. Recently, Anabousy and Tabach [21,22] examined the development of in-service teachers' knowledge and practices after their participating in a community-of-inquiry based PD program in which the teachers engaged in three inquiry cycles. The researchers (ibid) found that the participating teachers developed their knowledge as well as their practices related to technology integration after their participating in a such program. Similarly, other researchers suggest trajectories for preparing pre-service teachers and in-service teachers for integrating technology in their teaching [11, 23]. These trajectories could serve effective preparation of pre-service teachers' and in-service teachers. The present research also suggests one such trajectory, in addition to studying the effect of such trajectory on the pre-service teachers' acceptance of digital tools for teaching mathematics and science. The present research follows previous studies that emphasized the importance of studying the acceptance of digital tools by users [24].

\section{2-3-Technology Acceptance Model (TAM)}

One of the most widely used models for technology adoption and usage is the 'Technology Acceptance Model' (TAM) developed by Davis [2]. TAM assumes that perceived ease-of-use (PEOU) and perceived usefulness (PU) determine the user's acceptance of a technology. Davis describes PEOU as the degree to which the user expects the technology to be free of effort, whilePU is the individual's subjective perception of the technology as increasing performance within an organizational context. As shown in Figure 1, the TAM model suggests that the user's actual usage of a particular system develops over four stages. External variables as individual abilities and situational constraints influence technology usage through their impact on the PEOU and PU. Both factors (PEOU and PU) affect a user's attitude towards the technology, which in turn influences the user's intentionto use the technology. Furthermore, there is a direct impact of perceived usefulness on the user's intention to use the technology, which could mean that even if the individual has a negative attitude towards a technology, this could be overcome by a positive belief about the technology's usefulness, which finally leads to a positive usage intention [25]. 


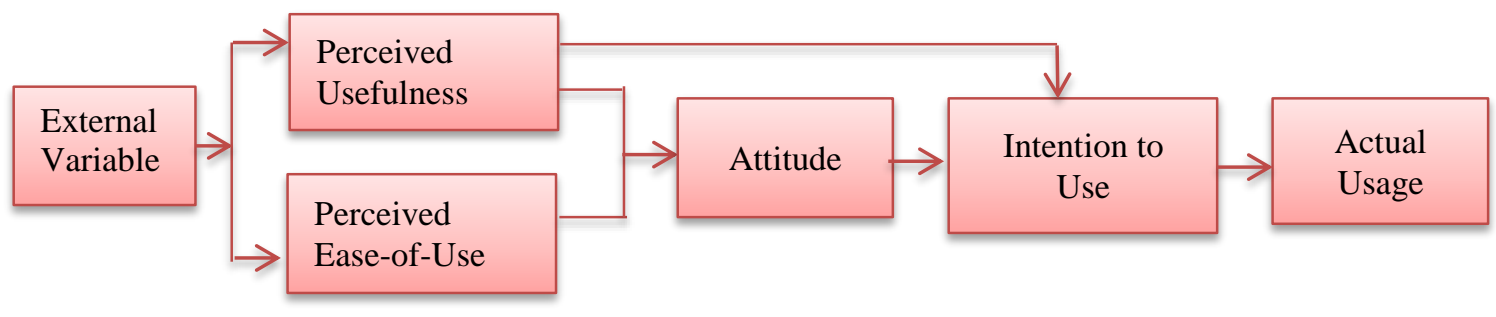

Figure 1. Original technology acceptance model as in Davis [2].

Alenezi et al. [26] used 'enjoyment', 'computer anxiety', 'computer self-efficacy' (CSE) and 'internet experience', in combination with PEOU and PU, to explain users' attitudes towards using E- learning. They found that computer anxiety, CSE and enjoyment significantly influenced students' intention to use E-learning, while the Internet experience insignificantly influenced them. Alenezi et al. [26], in contrast to Shih and Huang [27], found that attitude was confirmed to mediate the relationship between PU, PEOU and the users' behavioral intention. Results from Yi and Hwang [28] highlighted the important roles of self-efficacy, enjoyment, and learning goals orientation in determining the actual use of web-based information systems. In the present research, we examined whether the affective-psychological variables (self-efficacy, enjoyment and anxiety) mediate between the constructs of accepting digital tools for teaching mathematics and science.

\section{2-4- Affective and Psychological Variable as Mediator Variables in Technology-Based Learning}

Affective and psychological variables have been found to mediate the relationship between educational variables in the presence of technology. Al Dafaei et al. [29] examined whether self-efficacy significantly mediates the relationship between attitudes and level of use of instructional computer technology. They found that self-efficacy fully mediates the previous relationship. $\mathrm{Li}$ and Tsai [30] found that in the online game industry, self-efficacy mediates the effects of both learning orientation and affective commitment on group efficacy, where this mediation further facilitates innovation effectiveness.

Research related to students' enjoyment showed that some educational variables could mediate the relationship in which the students' enjoyment is an outcome variable. Frenzel et al. [31] found that teacher and student enjoyment were positively related. Moreover, the effect of teacher enjoyment on student enjoyment was mediated by teacher enthusiasm. In addition, Yu et al. [32] found that enjoyment, anxiety and boredom had significant mediating and moderating effects on the relationship between students' interaction and learning persistence in online settings.

Alenezi et al. [26] examined attitude, which is one component of TAM, as mediating the relationship between perceived usefulness, perceived ease of use and the students' behavioral intention. They found that attitude towards using E-learning fully mediated the relationship between perceived usefulness and behavioral intention to use E-learning. Further, they found that attitude towards using E-learning partially mediated the relationship between perceived ease of use and behavioral intention to use E-learning. Little research has considered affective variables that are not part of the original TAM as mediators between the components of TAM. The present research attempts to do so.

\section{3- Research Rationale and Goals}

Different studies examined students' acceptance of technological tools, but little research examined pre-service teachers' acceptance of digital tools for mathematics and science teaching, especially as a result of their preparation, specifically when affective constructs are considered as mediators of this acceptance. The present study attempts to do so, considering self-efficacy, enjoyment and anxiety as personal constructs that could mediate between the constructs of pre-service teachers' acceptance to use digital tools in their teaching. Doing so, one of the present study goals is to examine whether pre-service teachers' preparation develops their acceptance of these tools as teaching tools. Here, acceptance is measured in terms of the TAM components, i.e. PEOU, PU, CSE, attitude and future use. As mentioned above, another goal is to examine the mediation of self-efficacy, anxiety of usingdigital tools for teaching and enjoyment of this use between the constructs of TAM.

We addressed in our previous research the influence of the preparation program on some educational variables related to preservice teachers. Anabousy and Tabach [22] studied the influence of a preparation program on the participating teachers' metacognitive thinking, where here we investigate this influence on the preservice teachers' acceptance of digital tools for teaching. In addition, the preparation model that we suggest here summarizes our work with preservice teachers for more than a decade.

The mediators in which the present research is interested have been addressed in studies that use the TAM theoretical framework, but they have been studied as external variables, where little research has focused on them as mediators. 
Due to their potentiality to be mediators as the literature above indicates, research is needed to verify their mediation in the frame of TAM.

Drijvers [33] points out that the integration of digital technology in the classroom confronts teachers, educators and researchers with many questions. One such question is about the potential of ICT for mathematics learning and teaching, and which factors are critical in making it effective in the mathematics classroom. The present research attempts to study one aspect of this question, which is related to affective and behavioral aspects of the technology integration in the mathematics classroom. Moreover, this aspect could be studied by using the technology acceptance model as it could be applied to pre-service teachers' acceptance of digital tools for their teaching.

\section{4- Research Questions}

- Does the preparation of pre-service teachers in the use of digital tools increase their acceptance of these tools for teaching mathematics and science?

- Does the preparation result in significant differences in the scores of the different constructs of pre-service teachers' acceptance of digital tools (for teaching mathematics and science) according to the pre-service teachers' specialization, computer-ability and computer-use?

- Do CSE, anxiety of using digital tools for teaching mathematics and science and enjoyment of this use mediate between PEOU and PU on one side and attitude towards this use on the other side?

- Do CSE, anxiety of using digital tools for teaching mathematics and science and enjoyment of this use mediate between attitude towards this use on one side and intention to use on the other side?

\section{5- Research Methodology}

\section{5-1- Research Design}

The present research follows qualitative and quantitative analysis. The qualitative analysis uses the constant deductive and inductive constant comparison method, which helped arrive at the preparation model followed to educate the preservice teachers to use digital tools in teaching. The quantitative analysis was used to examine the influence of the educating program on the pre-service teachers' development in accepting digital tools for teaching. It was also used to investigate the mediation of the affective and psychological variables (enjoyment, self-efficacy, and anxiety) between the constructs of the TAM model. Before carrying out the required statistical tests, we investigated the assumptions of the tests. This included the paired sample t-test, as well as the mediation analysis. To carry out the mediation analysis, we depended on the regression analysis, so we investigated first the assumptions of the regression analysis.

\section{5-2- Research Procedure}

We prepared the educating program according to the student-in-the-center approach, where the pre-service teachers were given the autonomy to prepare technology-based lessons, discuss them in their groups, implement them in their training classrooms, reflect on this implementation and start the cycle again benefiting from the previous cycle. More detail is given in the results' section. We distributed the questionnaire at the beginning of the educational program and at its end. In addition, we requested the pre-service teachers to audio record their discussions and reflections, and to deliver the recordings to us. The pre-service teachers signed a formal consent form stating that they agree to participate in the research.

\section{5-3- Research Context and Participants}

The current research accompanies the preparation of third year pre-service teachers to use digital tools effectively in teaching mathematics and science. The preparation of the pre-service teachers in the college lasts four years, where the third year is the year in which the pre-service teachers are prepared to use digital tools in their teaching in the training schools. In their first year, the pre-service teachers participate in a course that focuses on technological skills as skills to use editorsand spreadsheets. In their second year, the pre-service teachers participate in a course that focuseson integrating technology in teaching the discipline, as mathematics or science.

We administered questionnaires to measure the advancement of the pre-service teachers' acceptanceof digital tools in teaching mathematics and science. Forty-eight pre-service teachers majoring in mathematics and science teaching (twenty-four in each discipline) completed the questionnaires at the beginning and end of the preparation.

\section{5-4- Research Instruments}

A questionnaire that is based on Davis' Technology Acceptance Model [2], with 7-point Likert items, was translated to conduct the research. Since TAM variations in different previous studies were all reliable, factor analysis was not carried out in this study. Instead, face validity and reliability (Cronbach's Alpha) calculations were carried out. Six scales 
were used. The first scale is the scale of digital tools usefulness (9 items), such as "Using digital tools would improve my problem solving". The second scale is the scale of digital tools' ease-of-use ( 3 items), such as "It would be easy for me to become skillful in digital tools". The third scale is the attitude towards digital tools ( 3 items), such as "I think digital tools should be used in the science classroom". The fourth scale is the intention-to-use scale (5 items), such as "I would use digital tools for teaching". The fifth scale is the use of digital tools (3 items), such as "I use digital tools in my teaching". The sixth scale is self-efficacy in using digital tools (5 items), such as "I can use digital tools for solving problems". The seventh scale is the enjoyment in teaching with digital tools (5 items), such as "Using digital tools in teaching is highly enjoyable". The eighth scale is the anxiety of teaching with digital tools, such as "I feel anxious when teaching with digital tools". The added constructs (self-efficacy and anxiety) were taken from Sánchez-Prieto et al. [34], while the enjoyment scale was taken from [35].

The questionnaire had two parts. The first part collected personal information as specialization, computer-ability, and computer-use, while the second part was composed of the eight scales. The questionnaire was translated for the first time to Arabic language before administering it to the pre-service teachers. The items in all the scales utilized 7-point scales ('strongly disagree' to 'strongly agree'). The questionnaire underwent validity and reliability tests.

Face Validity: The Arabic translation of the questionnaire was given to a group of pre-service teachers who were required to examine if the scales' statements were understandable to the reader. Some items of the scales were restated to clarify their ambiguity.

Content Validity: The questionnaire was given to a group of experts (five college instructors) who were required to examine whether the questionnaires' items cover the full domain of the different educational constructs and whether they cover constructs other than the appropriate ones. The experts gave no remarks that necessitated the modification of the TAM questionnaire.

The Scales' Reliability: The scores of the pre-service teachers in the TAM questionnaires were usedto compute Cronbach alpha of the various TAM constructs. The computations resulted in values that ranged between 0.82 and 0.91 , which are considered acceptable reliability scores.

\section{5-5- Data Analysis}

\section{Assumptions of Statistical Tests}

First, we tested the satisfaction of the assumptions of the statistical tests. The first research question was answered using paired-samples t-test. Laerd [36] describes 4 assumptions of the paired-sample t-test. The first assumption requires that the dependent variable should be measured on a continuous scale (i.e., it is measured at the interval or ratio level). This is satisfied in the case of the variables in the present research, as all the variables in TAM model, as well as the additional variables are continuous ones. The second assumption requires that the independent variable should consist of two categorical, "related groups" or "matched pairs". "Related groups" are groups in which the same subjects are present in both groups. In the present research, the two groups are the pre-service teachers' whose TAM and additional variables were measured before and after participating in the digital tools' preparation program. The third assumption requires that there should be no significant outliers in the differences between the two related groups. The outliers are identified on the box plot that SPSS produces for outliers, as cases below or above the end of each "whisker." To elaborate, SPSS identifies outliers as cases that fall more than 1.5 box lengths from the lower or upper hinge of the box, where the box length is defined as the distance from one hinge of the box to the other hinge. SPSS further distinguishes "extreme" outliers by identifying values more than 3 box lengths from either hinge [37]. Not all researchers are comfortable using the absolute value of 1.5 to judge outlier cases. Field and Miles [38] suggest that a value that lies between 1.5 and 3 times beyond the length of the box is considered a mild outlier, while a value that lies more than 3 times the length of the box is considered an extreme outlier. In addition, Hoaglin and Iglewicz [39] argue that the 1.5 multiplier is incorrect in outlier recognition roughly $50 \%$ of the time, so they suggest 2.2 as the most accurate multiplier to use. The previous argument made us look at 3 as multiplier as determining outliers, where the computations showed no such outliers. The fourth assumption requires that the distribution of the differences in the dependent variable between the two related groups should be approximately normally distributed. To investigate the normality assumption, we used Shapiro-Wilk test, as it is more appropriate for small sample sizes ( $<50$ samples) [40]. This assumption was satisfied as the significance of the statistic was more than .05 for all the research variables. The satisfaction of the previous four assumptions indicated that the paired-sample t-test could be used.

The second research question was answered using ANOVA. Laerd [41] describes six assumptions that need to be satisfied in order to carry out ANOVA. The first assumption is that the dependent variable should be continuous, where this is satisfied for all the current research variables. The second assumption is that the independent variable should consist of two or more categorical, independent groups. This is also satisfied in the current research as we are talking about specialization, computer-ability and computer-use that each has at least three values. The third assumption is that you have independent observations, where this assumption is satisfied as each group of participants is independent from 
the other. The fourth assumption requires that there should be no significant outliers. This was satisfied, taking into consideration 3 as multiplier of the length of the outliers' box. The fifth assumption is that the dependent variable should be approximately normally distributed for each category of the independent variable. The fifth assumption was tested using used Shapiro-Wilk test, where this test gave statistics with more than .05 significance, which showed normality of the dependent variable over each group of the independent variable. The sixth assumption requires the homogeneity of variances. This assumption was tested in SPSS Statistics using Levene's test for homogeneity of variances, which gave statistics with significance which is more than .05 , indicating the homogeneity of variances of the dependent variables over the groups of the independent variables. The satisfaction of the six assumptions made it possible to carry out ANOVA test.

Research questions 3 and 4 were answered using the four steps of Baron and Kenny [42]. Mediation analysis uses regression analysis and requests that the assumptions of regression be satisfied. Regression analysis requests the satisfaction of eight assumptions [43]. The first assumption is that the dependent variable should be measured on a continuous scale, where we reported the satisfaction of this assumption above. The second assumption is that there are two or more independent variables, which can be either continuous or categorical. In the third and fourth questions, the independent variables are all continuous, so the second assumption is met. The third assumption requests independence of observations, which can be checked using the Durbin-Watson statistic. Independence of observations is met when the Durbin-Watson statistic is between 1.5 and 2.5 and the p-value is above 0.05 . In the present research, we computed Durbin-Watson statistic for each mediation, where all the computations showed statistic lying between 1.5 and 2.5 and the p-value was above 0.05 [44]. The fourth assumption is that there needs to be a linear relationship between (a) the dependent variable and each of your independent variables, and (b) the dependent variable and the independent variables collectively. One way to do that is through creating a normal P-P Plot of Regression Standardized Residual. Figure 1 shows one such relationship normal P-P Plot of Regression Standardized Residual when the dependent variable is ease of use.

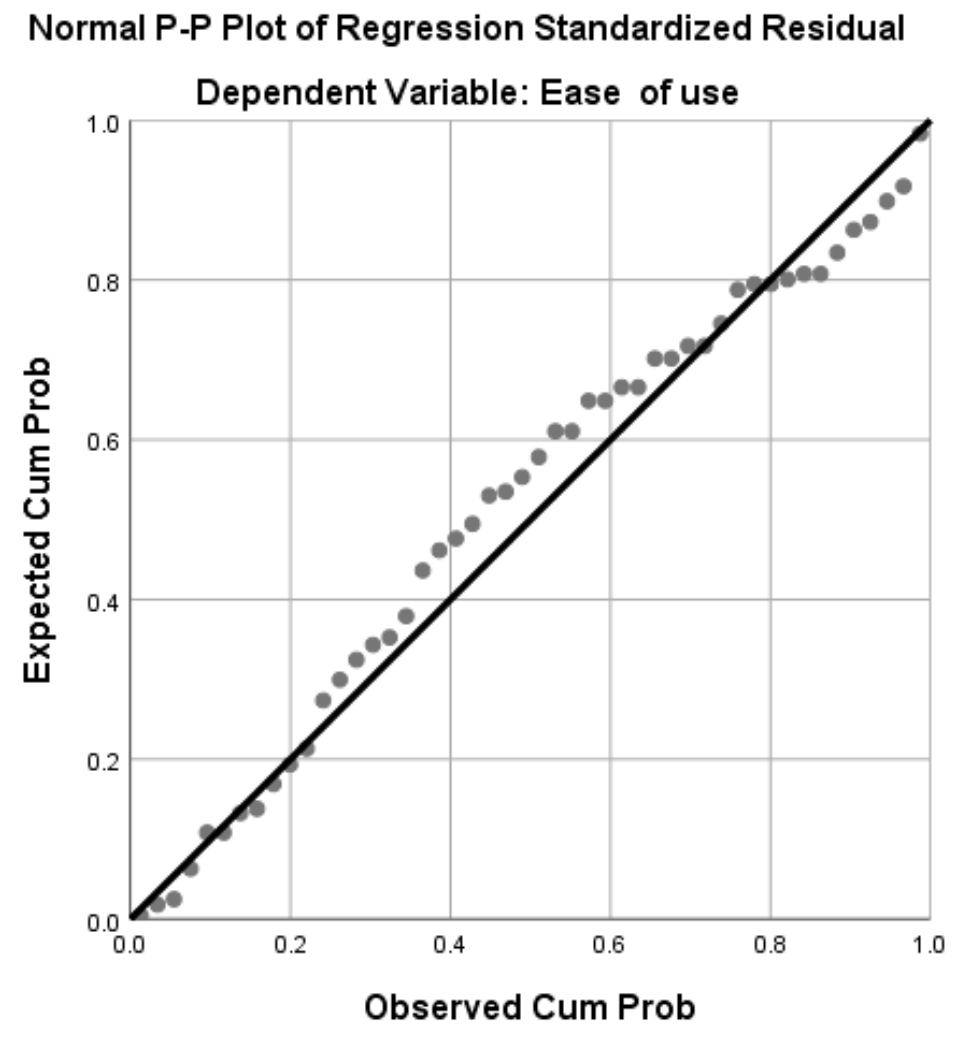

Figure 2. Normal P-P plot of regression standardized residual.

The fifth assumption requests that the data shows homoscedasticity, which is where the variances along the line of best fit remain similar as you move along the line. In addition, it does not have an obvious pattern, there are points equally distributed above and below zero on the $\mathrm{X}$ axis, and to the left and right of zero on the $\mathrm{Y}$ axis [45]. Figure 3 shows one such scatterplot, when the dependent variable is intention to use. 


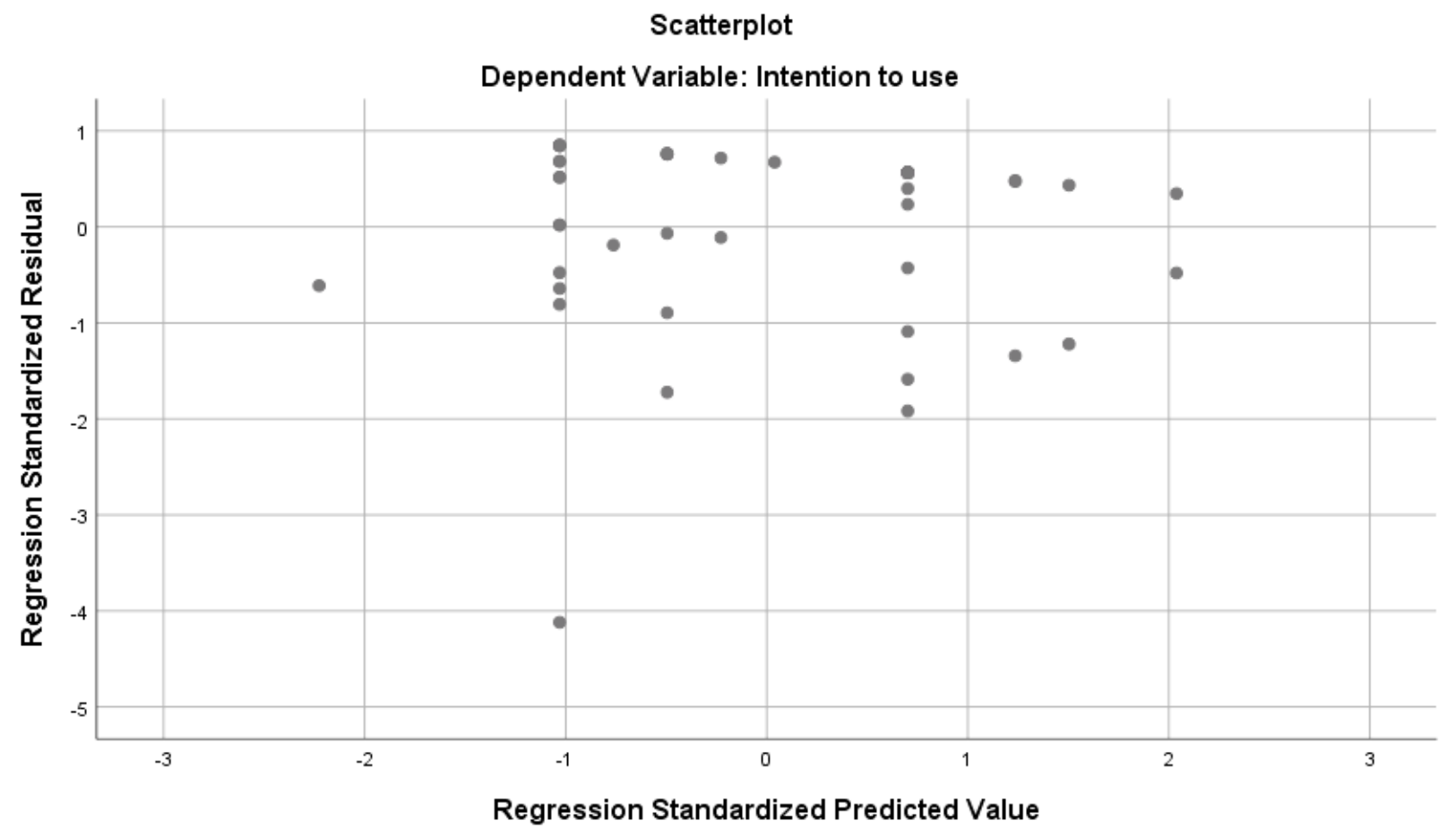

Figure 3. Standardized residuals.

The sixth assumption requests that the data must not show multicollinearity, which occurs when two or more independent variables are highly correlated with each other. This happens when the correlation is greater than 0.9 [46]. Computing correlations between the independent variables, all of them were less than 0.9 , as in Table 1, which proved the absence of multicollinearity.

Table 1. Pearson correlations between the independent variables.

\begin{tabular}{|c|c|c|c|c|}
\hline & & & Enjoyment & Self_efficacy \\
\hline \multirow{3}{*}{$\begin{array}{l}\text { Mediation of enjoyment and self-efficacy } \\
\text { between ease of use on one side and } \\
\text { attitude on the other side. }\end{array}$} & \multirow{3}{*}{ Ease_of_use } & Pearson Correlation & $0.522^{* *}$ & $0.513^{* *}$ \\
\hline & & Sig. (2-tailed) & 0.000 & 0.000 \\
\hline & & $\mathrm{N}$ & 48 & 48 \\
\hline \multirow{3}{*}{$\begin{array}{l}\text { Mediation of enjoyment and self-efficacy } \\
\text { between usefulness on one side and } \\
\text { attitude on the other side. }\end{array}$} & \multirow{3}{*}{ Usefulness } & Pearson Correlation & $0.573^{* *}$ & $.468^{* *}$ \\
\hline & & Sig. (2-tailed) & .000 & .000 \\
\hline & & $\mathrm{N}$ & 48 & 48 \\
\hline \multirow{3}{*}{$\begin{array}{l}\text { Mediations of enjoyment and self-efficacy } \\
\text { between attitude on one side and intention } \\
\text { to use on the other side. }\end{array}$} & \multirow{3}{*}{ Attitude } & Pearson Correlation & $0.549^{* *}$ & $0.463^{* *}$ \\
\hline & & Sig. (2-tailed) & 0.000 & 0.000 \\
\hline & & $\mathrm{N}$ & 48 & 48 \\
\hline
\end{tabular}

The seventh assumption requested that the data show no significant outliers, high leverage points or highly influential points. This assumption was satisfied as we reported above regarding the satisfaction of the outliers' assumption for the paired t-test. The eighth assumption requested that the residuals (errors) are approximately normally distributed. This assumption was also satisfied as we reported above regarding the satisfaction of the normality assumption for the paired t-test.

\section{Statistical Tests}

Research question 1 was answered using paired-samples t-test. Research question 2 was answered using ANOVA. Research questions 3 and 4 were answered using the four steps of Baron and Kenny [42]. 


\section{6- Results}

\section{6-1- The Preparation Model}

The pre-service teachers' preparation utilized a community of inquiry pedagogy [47] as well as practice-based or practice-oriented view of PD [48, 49]. The utilization of the two previous frameworks targeted developing mathematics and science pre-service teachers' practice in working with digital tools for teaching. More specifically, the present preparation targeted developing pre-service teachers' selection of a digital tool for a specific topic, in addition to teaching a specific topic with the selected digital tool.

The preparation model depended on the interaction between the pre-service teachers in an electronic forum designed for discussing the selection of digital tools for specific topics, utilizing them in lesson plans and implementing them in the mathematics and science classrooms. The three authors of the paper functioned as educators of the pre-service teachers in the forums, discussing with them issues that the pre-service teachers or the educators raised. The discussion also happened at office hours between the pre-service teachers and their educators.

Moreover, the pre-service teachers' preparation concentrated on two aspects. First, knowing the tool technically (technological knowledge) and pedagogically (pedagogical knowledge) and being able to suggest it for teaching a mathematical or scientific content (TPCK). Second, being able to start from a specific content, and select and integrate appropriate digital tools for its teaching (another aspect of PTK). In more detail, each pre-service teacher had to learn at least two digital tools technically by himself/herself and prepare user guides (PDF file or digital book) for other teachers that include description of the most significant operations in these digital tools. Furthermore, the pre-service teacher had to record video clips of screen shots while performing operations in these digital tools in order to explain for the users how to perform these operations.

Moreover, each pre-service teacher was required to prepare pedagogical materials of how to use the digital tools in teaching mathematics or science, and then present the materials in the training workshop and afterwards in the electronic forum. Following that, all the materials were uploaded to internet sites that were constructed by the pre-service teachers. An internet site was constructed by the pre-service teachers' educators that included all the materials prepared by the pre-service teachers, where these materials constituted a data bank for digital tools. In addition, each pre-service teacher was requested to prepare at least two lessons for teaching mathematics or science using three digital tools from the data bank. These lessons had to involve also collaborative learning and investigations that encourage the use of higher order thinking skills. In addition, each pre-service teacher chose a subject in a digital textbook for teaching mathematics or science, adding layers on it that connect to pedagogical activities based on using digital tools from the data bank site. All these issues were discussed by all the pre-service teachers in the electronic forum, as well as in the office hours of the pre-service teachers' educators.

All the previous happened in the first semester. In the second semester, the pre-service teachers were asked to experiment with the prepared materials and lessons in their training schools, reflect on their experimenting and then improve the lesson plans that they built before. All the previous steps were practice-based and intended to develop the pre-service teachers' practice of using digital tools in the science and mathematics classrooms. Figure 4 describes the preparation model that we followed to encourage the pre-service teachers to adopt digital tools for teaching mathematics and science.
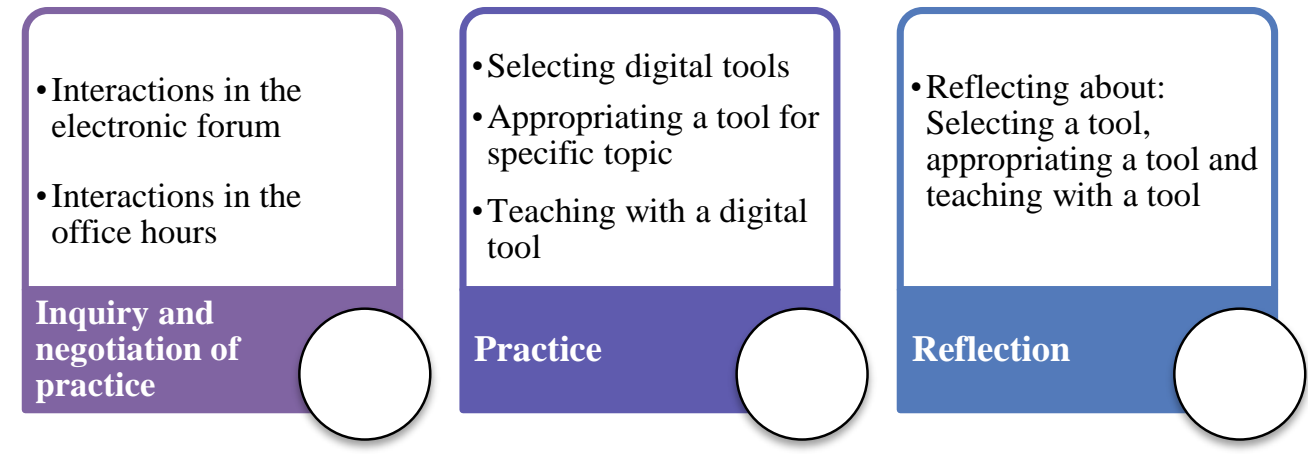

- Adjustment of how to select a tool, how to appropriate a tool and how to utilize a tool for teaching

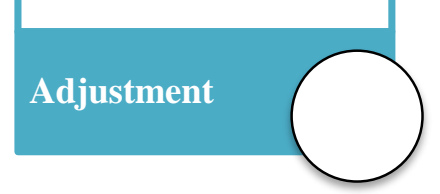

Figure 4. Teachers' preparation model for adopting digital tools for teaching.

\section{6-2- The Effect of the Preparation Model on the Participating Pre-Service Teachers' Acceptance of Digital Tools for Mathematics and Science Teaching}

The present research examined the influence of using a specific model (described above) to prepare pre-service teachers for using digital tools through one academic year. Doing so, we computed means and standard deviations of the scores of the different constructs of accepting digital tools for mathematics and science teaching. We also ran paired ttest to examine whether the differences between the scores before and after the intervention were significant. Table 2 shows the results of the previous computations. 
Table 2. Means, standard deviations, $T$ value of the scores of the different constructs of acceptance of digital tools for mathematics teaching $(\mathrm{N}=48)$.

\begin{tabular}{cccc}
\hline Category & Pre-Mean $(\mathbf{S D})$ & Post- Mean $(\mathbf{S D})$ & T value \\
\hline Ease of use & $5.23(1.29)$ & $6.05(1.13)$ & $5.31^{* * *}$ \\
Usefulness & $5.69(1.11)$ & $6.15(1.11)$ & $2.80^{* *}$ \\
Attitude & $5.72(1.19)$ & $6.18(1.13)$ & $2.82^{* *}$ \\
Intention to use & $5.83(1.11)$ & $6.18(1.20)$ & $2.39^{*}$ \\
Use & $5.14(1.48)$ & $6.18(1.18)$ & $4.21^{* * *}$ \\
Self-efficacy & $5.80(1.13)$ & $6.16(1.15)$ & $2.23^{*}$ \\
Anxiety & $3.00(1.83)$ & $3.33(2.28)$ & 0.79 \\
Enjoyment & $5.71(1.31)$ & $6.15(1.20)$ & $2.58^{*}$ \\
\hline
\end{tabular}

$* \mathrm{p}<.05, * * \mathrm{p}<.01, * * * \mathrm{p}<0.001$

Table 2 shows that using the model described above to prepare pre-service teachers for using digital tools through one academic year resulted in significant differences in the scores of the different components of TAM and the affective variables, except in the scores of anxiety.

We measured the effect size related to the differences that resulted from the intervention, using Cohen's d [50], where 0.8 is considered a large effect size, 0.5 is considered a medium effect size and 0.2 a weak one. Doing so, we found that the effect size of the intervention for "ease of use" $(\mathrm{d}=0.78)$ was found to be a large effect, while the effect size of the intervention for "usefulness" (0.405), "use" (0.406) and "intention to use" (0.607) were found to be medium effects. In addition, the effect size of the intervention for "attitude" (0.33), "self-efficacy" (0.33) and "enjoyment" (0.37) were found to be weak effects.

Another goal of the present research was to examine whether the independent variables (specialization, computerability, and computer-use) influenced the results of the intervention. Doing so, we ran mixed way ANOVA which showed no significant interaction at the level of 0.05 or lower.

A third goal of the present study was to examine the mediation of enjoyment, anxiety and self- efficacy between the predictors ease-of-use and usefulness, and the outcomes attitude and use. At the beginning, Pearson correlations were computed, which showed non-significant correlations with anxiety. So, anxiety was not considered as mediator construct. Moreover, self-efficacy and enjoyment were examined as mediators between ease-of-use and usefulness and between attitudes (first mediation). Afterwards, self-efficacy and enjoyment were examined as mediators between attitude and the intention to use digital tools in teaching (second mediation).

In Step 1 of examining the first mediation, the regression of attitude as outcome on the predictors, ease of use and usefulness scores, ignoring the mediator, was significant, $b=0.94, t(47)=1.71, p=0.000$ for ease of use and $b=0.96$, $\mathrm{t}(47)=24.28, \mathrm{p}=0.000$ for usefulness. Step 2 showed that the regression of the mediators' scores, self-efficacy and enjoyment, on the predictors, was also significant, $b=0.91, t(47)=15.22, p=0.000$ for self-efficacy on ease-of-use; $b=$ $0.97, t(47)=26.35, p=0.000$ for self-efficacy on usefulness; $b=0.92, t(47)=16.13, p=.000$ for enjoyment on ease-ofuse; $\mathrm{b}=0.97, \mathrm{t}(47)=28.39, \mathrm{p}=0.000$ for enjoyment on usefulness. Step 3 of the mediation process showed that the regression of attitude scores on the mediators was also significant, $b=0.96, t(47)=24.19, p=0.000$ on self-efficacy and $b=0.95, t(47)=20.39, p=.000$ on enjoyment. Step 4 of the mediation process showed that the regression of the attitude on the ease-of-use controlling for enjoyment as a mediator was also significant, $b=0.46, t(47)=4.57, p=0.000$. This shows partial mediation of enjoyment as the effect of ease-of-use has dropped from 0.94 to 0.46 . Partial mediation was obtained too for self-efficacy as mediator between attitude and ease-of-use, $b=0.39, t(47)=4.81, p=0.000$, where the effect of ease-of-use has dropped from 0.94 to 0.39 . The same computations in step 4 were carried out for the mediators between attitude, as outcome, and usefulness, as predictor. These computations showed partial mediation regarding self-efficacy and no mediation regarding enjoyment.

As to the second mediation, computing for mediation effects for intention to use as outcome and attitude towards use as predictor, the first three steps showed significant results for self-efficacy and enjoyment as mediators. Step 4 showed partial mediation of self-efficacy, where the effect of attitude on the intention to use has dropped from 0.95 to 0.31 . It also showed partial mediation of enjoyment, where the effect of attitude on the intention to use has dropped from 0.95 to 0.36 . Figure 5 shows the appropriate regression weights. 


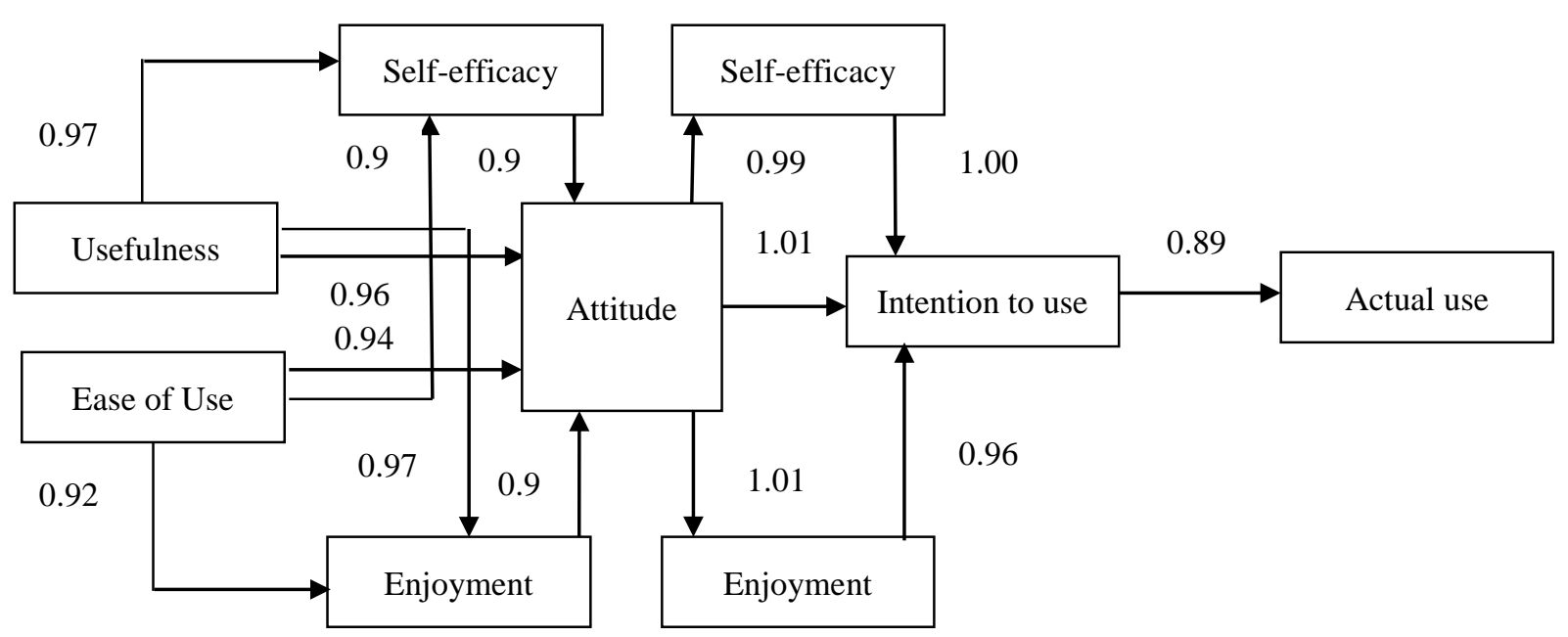

Figure 5. Regression analysis of the TAM constructs for pre-service teachers' acceptance of digital tools for teaching.

\section{7- Discussion}

The present research examined the influence of using a specific model in the preparation of pre-service teachers for using digital tools through community of inquiry practices and practice-based PD. The research results indicate that the preparation resulted in significant differences in the scores of the different constructs, except anxiety, of the acceptance of digital tools for teaching mathematics and science. Thus, the results show the effectiveness of the community of inquiry practices $[11,18,22,47,51]$ regarding the acceptance of technology for teaching, where these practices included synchronous as well as asynchronous means of communication. It is our conclusion that both means are essential in preservice teachers' education [52]. The results also show the effectiveness of practice-based PD [48] which included the two effective means [53]: pre-service teachers' access to the digital tools, and the actual opportunities they had during the preparation year to utilize these tools in their teaching.

As a result of the synchronous and the asynchronous means of communication, the pre-service teachers increased significantly the mean score of the different constructs that are part of the original TAM framework. It seems that increasing the pre-service teachers' ease-of-Use and usefulness related to using digital tools in teaching also increased the participants' attitude, intention to use and use of digital tools in teaching. This is in line with previous studies that indicated the positive role of preparation for teaching with technology. For example, Theelen et al. [54] found that the video-lecture combination led to a reduced professional anxiety and increased self-efficacy of the pre-service teachers who participated in the experiment. Thus, technology-based preparation programs not only improve pre-service teachers' practices and perceptions of technology integration in the classroom but their teaching in general.

The research results showed insignificant differences in the scores of anxiety to use ICT tools in the mathematics and science classrooms. These scores were already low before the preparation (Mean $=3.00$, where the minimum score of each item was 1 and the maximum was 7) as a result of the pre-service teachers' preparation in their first two years of study. So, it was expected that it would stay low after the preparation. The results indicate the importance of preparation that is needed to reduce the high levels of teachers' anxiety or stress due to their use of educational technology in the classroom [55]. Setyarini (2018) [56] reported that teachers experienced computer anxiety with different psychological and physical symptoms. This computer anxiety was caused by four factors: social matter, psychological matter, teachers' ability and technical matters. The pre-service teachers' preparation included taking courses related to technology and computer applications, where this preparation considered the educational uses of the applications. Thus, it could be argued that the preparation helped the pre-service teachers lessen their anxiety of using ICT as part of their teaching, specifically anxiety related to their ability and to the technical matters of using technology in teaching. Setyarini (2018) [56] gives an example on technical matters the issue of whether the programs or devices that they used would work as they expected. It is obvious that educating pre-service teachers to use technology, including for teaching in the classroom, as in the case of the pre-service teachers in the present research, probably made those pre-service teachers able to overcome difficulties related to technical matters.

In addition, Revilla Munoz et al. [57] reported an experiment in which they built a course that targeted improving high school teachers' ICT problem solving skills, where this improvement resulted in reducing techno-anxiety of these high school teachers. On the other hand, improving digital skills could improve other educational constructs as the leadership ones [58]. The previous argument indicates the importance of preparation programs that target in-service and pre-service teachers' ICT skills and the integration of ICT in teaching. In our case, the preparation program affected positively the participants' constructs related to the acceptance of digital tools in teaching. 
Running mixed way ANOVA showed that the background variables (specialization, computer-ability, computer-use) did not interact significantly with the intervention. This insignificant interaction indicates that the intervention influenced positively all the pre-service teachers, and not only part of them. We expected that the intervention would benefit the science pre-service teachers more because the mathematics pre-service teachers are specialized in computers too. It seems that this did not happen because the intervention was involved with technological pedagogical content knowledge which was developed in the two groups of pre-serves teachers as a result of preparing them to integrate digital tools in teaching during one year. This has not much to do with the technological knowledge that the mathematics pre-service teachers are engaged with as part of their computer specialization. This technological knowledge is specific for computer topics that are not part of the middle school curriculum. Especially, they are not or little related to integrating technology in the mathematics classroom. What influenced the pre-service teachers' acceptance of digital tools for teaching is specifically the engagement in negotiating technological knowledge in the forums and as part of the reflection resulted in a teaching context that encourage the pre-service teachers to accept technology as part of their repertoire in the mathematics and science classrooms [11, 18].

The anxiety scores, being low, resulted in insignificant correlations with the other variables, what excluded anxiety from being a mediator between the variables of technology acceptance. Self- efficacy, which is a critical factor of personality [59], proved to be a partial mediator between ease-of-use and attitude, as well as between usefulness and attitude. Moreover, self-efficacy proved to be a partial mediator between attitude and intention-to-use. These results are in line with other studies that found self-efficacy to mediate between variables when at least part of these variables were affective [29-30].

At the same time, enjoyment proved to be a partial mediator between ease-of-use and attitude, but not between usefulness and attitude. In addition, enjoyment proved to be a partial mediator between attitude and intention-to-use. These results are in line with studies that found enjoyment to mediate between classroom variables [32].

\section{8- Conclusions, Limitations and Contribution}

Little research has been done on affective and psychological variables as mediators of the acceptance of digital tools for teaching by pre-service teachers. The present study investigated affective and psychological constructs, specifically enjoyment, self-efficacy and anxiety, as mediators in the acceptance of digital tools for teaching. More attention needs to be paid to the various affective and psychological constructs as mediators and antecedents for technology use in teaching mathematics and science, especially during teachers' preparation programs [60]. Thus, one limitation of the present research is that it was interested in enjoyment, self-efficacy and anxiety. Future research is needed to study other affective and psychological variables as mediators in the acceptance of technology. Examples on such variables are satisfaction, motivation and learning flow.

Another limitation of the study is that it involved only mathematics and science teachers. Future research is needed to study affective variable as mediators of the acceptance of digital teaching by in-service and pre-service teachers of other disciplines. A third limitation is that the present research is interested in mediators. Future research is needed to study the issue of moderation, i.e., to investigate affective and psychological variables as moderators of the acceptance of technology by teachers. A fourth limitation of the present research is that it is done in the frame of an education program for pre-service teachers. A future study is needed to investigate the issue of mediators and moderators in the acceptance of technology in the frame of a professional development program for in-service teachers.

Attention needs to be paid for the affective and psychological variables in teachers' educational program, especially when these programs address technology use in the classroom. These educational programs need to foster enjoyable learning experiences, so that the option of teachers' acceptance of technology or other innovation use in the classroom rises. To increase pre-service and pre-service teachers' self-efficacy in using technology for teaching, the educational programs need to design hands-on activities in which the participants prepare technology-based activities for teaching in the classroom, and implement these activities in the training or actual classroom.

\section{9- Declarations}

\section{9-1-Author Contributions}

Conceptualization, W.D. and N.B.; methodology, W.D.; software, N.B.; formal analysis, A.A.; investigation, W.D. and A.A; resources, N.B.; data curation, N.B.; writing, W.D.; writing - review and editing, N.B. and A.A.; supervision, N.B; project administration, N.B.; funding acquisition, Y.Y. All authors have read and agreed to the published version of the manuscript.

\section{9-2-Data Availability Statement}

The data presented in this study are available on request from the corresponding author. 


\section{9-3-Funding}

The authors received no financial support for the research, authorship, and/or publication of this article.

\section{9-4- Conflicts of Interest}

The authors declare that there is no conflict of interests regarding the publication of this manuscript. In addition, the ethical issues, including plagiarism, informed consent, misconduct, data fabrication and/or falsification, double publication and/or submission, and redundancies have been completely observed by the authors.

\section{0- References}

[1] Thomas, Michael O. J., and Joann M. Palmer. "Teaching with Digital Technology: Obstacles and Opportunities.” Mathematics Education in the Digital Era: An International Perspective on Technology Focused Professional Development (September 30, 2013): 71-89. doi:10.1007/978-94-007-4638-1_4.

[2] Davis, Fred D. "Perceived Usefulness, Perceived Ease of Use, and User Acceptance of Information Technology." MIS Quarterly 13, no. 3 (September 1989): 319. doi:10.2307/249008.

[3] Getenet, Seyum Tekeher, Kim Beswick, and Rosemary Callingham. "Conceptualising technology integrated mathematics teaching: The STAMP knowledge framework." In Proceedings of the 2015 annual conference for the psychology of mathematics education (PME 39), vol. 2, pp. 321-328. International Group for the Psychology of Mathematics Education (IGPME), 2015.

[4] Hong, Y. Y., and Thomas, M. O. J. "Factors influencing teacher integration of graphic calculators in teaching." Proceedings of the 11th Asian technology conference in mathematics. (2006):234-243. Hong Kong.

[5] Geiger, Vince, Helen Forgasz, Hazel Tan, Nigel Calder, and Janelle Hill. “Technology in Mathematics Education.” Research in Mathematics Education in Australasia 2008-2011 (2012): 111-141. doi:10.1007/978-94-6091-970-1_7..

[6] Daher, Wajeeh. "Preservice teachers' perceptions of applets for solving mathematical problems: Need, difficulties and functions." Journal of Educational Technology \& Society 12, no. 4 (2009): 383-395.

[7] Anabousy, A., and Tabach, M. "Constructing and Consolidating Mathematical Knowledge in GeoGebra environment by a pair of students." In K., Beswick, T., Muir, and J., Wells, (Eds.), Proceedings of the 39th Conference of the International Group for the Psychology of Mathematics Education, Vol. (2) (2015): 41-48. Hobart, Australia.

[8] Daher, Wajeeh. "Learning mathematics in the mobile phone environment: students' emotions." Journal of interactive learning research 22, no. 3 (2011): 357-378.

[9] Daher, W. "A teacher's ideology and its impact on students' positioning in problem solving." Philosophy of Mathematics Education Journal, 34 (2018).

[10] Daher, Wajeeh, and Osama Swidan. "Positioning-Emotions Association of Young Students Using Digital Technology." Mathematics 9, no. 14 (July 8, 2021): 1617. doi:10.3390/math9141617.

[11] Daher, Wajeeh, Nimer Baya'a, Otman Jaber, and Juhaina Awawdeh Shahbari. "A Trajectory for Advancing the Meta-Cognitive Solving of Mathematics-Based Programming Problems with Scratch.” Symmetry 12, no. 10 (October 2, 2020 ): 1627. doi:10.3390/sym12101627.

[12] Daher, Wajeeh, Kifaya Sabbah, and Maysa Abuzant. "Affective Engagement of Higher Education Students in an Online Course." Emerging Science Journal 5, no. 4 (August 1, 2021): 545-558. doi:10.28991/esj-2021-01296.

[13] Daher, Wajeeh, Ahlam Anabousy, and Roqaya Jabarin. "Metacognition, Positioning and Emotions in Mathematical Activities." International Journal of Research in Education and Science (January 24, 2018): 292-303. doi:10.21890/ijres.383184.

[14] Daher, Wajeeh. "Mathematics Learning Community Flourishes in the Cellular Phone Environment." International Journal of Mobile and Blended Learning 2, no. 2 (April 2010): 1-17. doi:10.4018/jmbl.2010040101.

[15] Daher, Wajeeh, and Juhaina Awawdeh Shahbari. "Secondary Students' Identities in the Virtual Classroom.” Sustainability 12, no. 11 (May 28, 2020): 4407. doi:10.3390/su12114407.

[16] Drijvers, P. "Head in the clouds, feet on the ground-A realistic view on using digital tools in mathematics education." In A. Büchter, M. Glade, R. Herold-Blasius, M. Klinger, F. Schacht, and P. Scherer (Eds.), Vielfältige Zugänge zum Mathematikunterricht (2019): 163-176. Wiesbaden: Springer.

[17] Jacobsen, Michele, Pat Clifford, and Sharon Friesen. "Preparing teachers for technology integration: Creating a culture of inquiry in the context of use." Contemporary issues in technology and teacher education 2, no. 3 (2002): 363-388.

[18] Baya, Nimer, Wajeeh Daher, and Ahlam Anabousy. "The Development of In-Service Mathematics Teachers' Integration of ICT in a Community of Practice: Teaching-in-Context Theory." International Journal of Emerging Technologies in Learning 14, no. 1 (2019). doi:10.3991/ijet.v14i01.9134. 
[19] Hedberg, H. E. "Technology integration professional development for teachers: Strategies for action" (2008). Colorado: Regis University ePublications at Regis University.

[20] "Building and Sustaining Inquiry Communities in Mathematics Teaching Development." International Handbook of Mathematics Teacher Education: Volume 3 (January 1, 2008): 309-330. doi:10.1163/9789087905491_015.

[21] Anabousy, A., and Tabach, M. "Teachers' Knowledge Development after Participation in a Community of Inquiry Professional Development Program." In M. Graven, H. Venkat, A. Essien and P. Vale (Eds.). Proceedings of the 43nd Conference of the International Group for the Psychology of Mathematics Education (Vol. 2, (2019): 17-24). Pretoria, South Africa.

[22] Anabousy, A., and Tabach, M. "The Development of Technological Craft Knowledge Within a Community of Inquiry." 14th International Congress in Mathematics Education (ICME14). (July 2021), Shanghai, China.

[23] Daher, Wajeeh, Baya'a. Nimer, Otman Jaber, and Ahlam Anabousy. "Developing pre-service mathematics teachers' metacognitive thinking for learning and teaching with mobile technology." The Eurasia Proceedings of Educational and Social Sciences 9 (2018): 239-249.

[24] Puriwat, Wilert, and Suchart Tripopsakul. "Understanding Food Delivery Mobile Application Technology Adoption: A UTAUT Model Integrating Perceived Fear of COVID-19.” Emerging Science Journal 5 (July 14, 2021): 94-104. doi:10.28991/esj-2021sper-08.

[25] Röcker, Carsten. "Perceived Usefulness and Perceived Ease-of-Use of Ambient Intelligence Applications in Office Environments." Lecture Notes in Computer Science (2009): 1052-1061. doi:10.1007/978-3-642-02806-9_120.

[26] Alenezi, Abdulhameed Rakan, and Abdul Karim. "An empirical investigation into the role of enjoyment, computer anxiety, computer self-efficacy and internet experience in influencing the students' intention to use e-learning: A case study from Saudi Arabian governmental universities." Turkish Online Journal of Educational Technology-TOJET 9, no. 4 (2010): 22-34.

[27] Shih, Ya-Yueh, and Siao-Sian Huang. "The actual usage of ERP systems: An extended technology acceptance perspective." Journal of Research and Practice in Information Technology 41, no. 3 (2009): 263-276.

[28] Yi, Mun Y, and Yujong Hwang. "Predicting the Use of Web-Based Information Systems: Self-Efficacy, Enjoyment, Learning Goal Orientation, and the Technology Acceptance Model." International Journal of Human-Computer Studies 59, no. 4 (October 2003): 431-449. doi:10.1016/s1071-5819(03)00114-9.

[29] Al Dafaei, Issa Mohamed, Zurida Ismail, Mohd Ali Samsudin, and J. F. Shakir. "The Mediating effect of self-Efficacy towards the Relationship between attitudes and level of use towards Instructional computer technology in Oman." International Journal of Asian Social Science 3, no. 12 (2013): 2382-2398.

[30] Li, Chia-Ying, and Chiun-Yi Tsai. "Multilevel Study of Factors for Cultivating Self-Efficacy in the Online Game Industry." Journal of Management \& Organization 25, no. 5 (May 22, 2017): 672-694. doi:10.1017/jmo.2017.22.

[31] Frenzel, Anne C., Thomas Goetz, Oliver Lüdtke, Reinhard Pekrun, and Rosemary E. Sutton. "Emotional Transmission in the Classroom: Exploring the Relationship Between Teacher and Student Enjoyment.” Journal of Educational Psychology 101, no. 3 (August 2009): 705-716. doi:10.1037/a0014695.

[32] Yu, Jianhui, Changqin Huang, Zhongmei Han, Tao He, and Ming Li. "Investigating the Influence of Interaction on Learning Persistence in Online Settings: Moderation or Mediation of Academic Emotions?” International Journal of Environmental Research and Public Health 17, no. 7 (March 30, 2020): 2320. doi:10.3390/ijerph17072320.

[33] Drijvers, Paul. "Digital Technology in Mathematics Education: Why It Works (Or Doesn't).” Selected Regular Lectures from the 12th International Congress on Mathematical Education (2015): 135-151. doi:10.1007/978-3-319-17187-6_8.

[34] Sánchez-Prieto, José Carlos, Susana Olmos-Migueláñez, and Francisco J. García-Peñalvo. "Informal Tools in Formal Contexts: Development of a Model to Assess the Acceptance of Mobile Technologies among Teachers." Computers in Human Behavior 55 (February 2016): 519-528. doi:10.1016/j.chb.2015.07.002.

[35] Park, Eunil, Seoin Baek, Jay Ohm, and Hyun Joon Chang. "Determinants of Player Acceptance of Mobile Social Network Games: An Application of Extended Technology Acceptance Model.” Telematics and Informatics 31, no. 1 (February 2014): 315. doi:10.1016/j.tele.2013.07.001.

[36] Laerd. "Dependent t-test using SPSS Statistics." (2018a). Available online: https://statistics.laerd.com/spss-tutorials/dependentt-test-using-spss-statistics.php (accessed on May 2021).

[37] Park, Eunil, Seoin Baek, Jay Ohm, and Hyun Joon Chang. "Determinants of Player Acceptance of Mobile Social Network Games: An Application of Extended Technology Acceptance Model.” Telematics and Informatics 31, no. 1 (February 2014): 315. doi:10.1016/j.tele.2013.07.001.

[38] Field, A. P., and Miles, J. "Discovering statistics using SAS: (and sex and drugs and rock n roll)" (2010). Thousand Oaks, CA: Sage.

[39] Hoaglin, David C., and Boris Iglewicz. "Fine-Tuning Some Resistant Rules for Outlier Labeling." Journal of the American Statistical Association 82, no. 400 (December 1987): 1147-1149. doi:10.1080/01621459.1987.10478551. 
[40] Laerd. "Testing for Normality using SPSS Statistics." (2018d). Available online: https://statistics.laerd.com/spsstutorials/testing-for-normality-using-spss-statistics.php (accessed on May 2021).

[41] Laerd. "One-way ANOVA in SPSS Statistics." (2018b).

[42] Baron, Reuben M., and David A. Kenny. "The moderator-mediator variable distinction in social psychological research: Conceptual, strategic, and statistical considerations." Journal of personality and social psychology 51, no. 6 (1986): 1173.

[43] Laerd (2018c). Multiple Regression Analysis using SPSS Statistics. Available online: https://statistics.laerd.com/spsstutorials/multiple-regression-using-spss-statistics.php (accessed on May 2021).

[44] Lester, P. E., Inman, D., and Bishop, L. "Handbook of test and measurement in education and in the social sciences" (2014). Lanham, Maryland: Rowman and Littlefield.

[45] Statistics Solutions. "Testing assumptions of linear regression in SPSS" (2021). Available online: https://www.statisticssolutions.com/testing-assumptions-of-linear-regression-in-spss/ (accessed on May 2021).

[46] Dohoo, I.R., C. Ducrot, C. Fourichon, A. Donald, and D. Hurnik. "An Overview of Techniques for Dealing with Large Numbers of Independent Variables in Epidemiologic Studies.” Preventive Veterinary Medicine 29, no. 3 (January 1997): 221-239. doi:10.1016/s0167-5877(96)01074-4.

[47] Jaworski, Barbara. "Learning Communities in Mathematics: Creating an Inquiry Community between Teachers and Didacticians.” Research in Mathematics Education 7, no. 1 (April 2005): 101-119. doi:10.1080/14794800008520148.

[48] Ball, Deborah Loewenberg, and Hyman Bass. "Toward a practice-based theory of mathematical knowledge for teaching." In Proceedings of the 2002 annual meeting of the Canadian Mathematics Education Study Group, Edmonton Alberta, (2002): 314.

[49] Da Ponte, João Pedro. “A Practice-Oriented Professional Development Programme to Support the Introduction of a New Mathematics Curriculum in Portugal." Journal of Mathematics Teacher Education 15, no. 4 (June 1, 2012): $317-327$. doi:10.1007/s10857-012-9219-y.

[50] Cohen, J. "Statistical power analysis Jbr the behavioral." Sciences. Hillsdale (NJ): Lawrence Erlbaum Associates, New York, NY: Routledge Academic (1988): 18-74.

[51] Jensen, Cory, Mohamed Kotaish, Aditi Chopra, Kiran A. Jacob, Taqdees I. Widekar, and Rahat Alam. "Piloting a Methodology for Sustainability Education: Project Examples and Exploratory Action Research Highlights.” Emerging Science Journal 3, no. 5 (October 1, 2019): 312-326. doi:10.28991/esj-2019-01194.

[52] Hrastinski, S. "Asynchronous and synchronous e-learning." Educause quarterly 31, no. 4 (2008): 51-55.

[53] Spector, J. M., E. Jakubowski, et al. "Investigating pre-service mathematics teachers' initial use of the next-Generation TI-Nspire graphing calculators: A case study." Tallahassee, FL: Florida Center for Research on STEM education (FCR-STEM), Learning Systems Institute, Florida State University. (2008).

[54] Theelen, H., A. van den Beemt, and P. den Brok. "Enhancing Authentic Learning Experiences in Teacher Education through 360-Degree Videos and Theoretical Lectures: Reducing Preservice Teachers’ Anxiety.” European Journal of Teacher Education (September 27, 2020): 1-20. doi:10.1080/02619768.2020.1827392.

[55] Fernández-Batanero, José-María, Pedro Román-Graván, Miguel-María Reyes-Rebollo, and Marta Montenegro-Rueda. "Impact of Educational Technology on Teacher Stress and Anxiety: A Literature Review.” International Journal of Environmental Research and Public Health 18, no. 2 (January 11, 2021): 548. doi:10.3390/ijerph18020548.

[56] Setyarini, Maria Christina Eko. “Understanding Teachers' Computer Anxiety.” ETERNAL (English Teaching Journal) 6, no. 1 (April 17, 2018). doi:10.26877/eternal.v6i1.2297.

[57] Revilla Muñoz, Olga, Francisco Alpiste Penalba, Joaquín Fernández Sánchez, and Olga C. Santos. "Reducing Techno-Anxiety in High School Teachers by Improving Their ICT Problem-Solving Skills.” Behaviour \& Information Technology 36, no. 3 (September 7, 2016): 255-268. doi:10.1080/0144929x.2016.1221462.

[58] Antonopoulou, Hera, Constantinos Halkiopoulos, Olympia Barlou, and Grigorios N. Beligiannis. "Transformational Leadership and Digital Skills in Higher Education Institutes: During the COVID-19 Pandemic.” Emerging Science Journal 5, no. 1 (February 1, 2021): 1-15. doi:10.28991/esj-2021-01252.

[59] Jabbari Ghazi Jahani, Hamed, Azadeh Ehsanikenari, and Afsaneh Sadat Sharif. "Role of Self-Efficacy and Negative Perfectionism in the Prediction of Procrastination of Narcissistic Personality: A Study on Non-Clinical Subjects." Emerging Science Journal 2, no. 6 (December 13, 2018): 388. doi:10.28991/esj-2018-01158.

[60] Thurm, D., Barzel, B. "Micro-teaching of landmark jobs -fostering self-efficacy for teaching mathematics with technology." The 14th International Congress in Mathematics Education (ICME14). (July 2021): 11-18. Shanghai, China. 